\title{
Acute Multiple Arteriovenous Thromboses in a Patient with Diabetic Ketoacidosis
}

\author{
Sayaka Wakabayashi ${ }^{1}$, Tetsuro Tsujimoto ${ }^{1}$, Miyako Kishimoto ${ }^{1}$, Nahoko Ikeda ${ }^{1}$, \\ Kaori Inoue ${ }^{1}$, Noriko Ihana ${ }^{1}$, Hidetaka Hamasaki ${ }^{1}$, Hiroshi Noto ${ }^{1,2}$, \\ Ritsuko Yamamoto-Honda ${ }^{1,2}$, Hiroshi Kajio ${ }^{1}$ and Mitsuhiko Noda ${ }^{1,2}$
}

\begin{abstract}
Diabetic ketoacidosis (DKA) is one of the most serious acute complications of diabetes mellitus. An arterial thrombotic tendency from DKA is relatively common; however, the occurrence of acute multiple arteriovenous thromboses is rare. We herein report the case of a 49-year-old man with DKA complicated by multiple thromboses. After transfer to our emergency room with DKA, the patient developed sudden abdominal pain. Contrast-enhanced computed tomography revealed near-complete occlusion of the superior mesenteric artery, superior mesenteric vein, splenic artery, and right femoral artery. This occurrence highlights the need for considering the risk of thrombosis during the initial treatment for DKA.
\end{abstract}

Key words: diabetic ketoacidosis, multiple thromboses, severe hyperglycemia

(Intern Med 54: 2025-2028, 2015)

(DOI: 10.2169/internalmedicine.54.4087)

\section{Introduction}

Diabetic ketoacidosis (DKA) is one of the most serious acute complications of diabetes mellitus. The mortality of patients due to DKA is as high as 5\% (1), and can reach $20 \%$ when complicated by thromboembolism (2). An arterial thrombotic tendency due to DKA is a relatively common concomitant life-threatening condition, although acute multiple arteriovenous thromboses in DKA is rare. In the present article, we report a case of DKA complicated with multiple thromboses.

\section{Case Report}

A 49-year-old man was transferred to the emergency room from another hospital because of symptoms of increasing lethargy. After an intravenous infusion of dopamine hydrochloride $(1.9 \mu \mathrm{g} / \mathrm{kg} / \mathrm{min})$, his blood pressure and heart rate were $84 / 50 \mathrm{mmHg}$ and 120 beats/min, respectively. He had a recent 3-month history of weight loss, and a recent 1- month history of fatigue, polydipsia, and polyuria. Furthermore, he had a history of hypertension, was a current smoker. However, he had no history of diabetes, cardiovascular disease, or hypercoagulable states such as antiphospholipid syndrome. His laboratory tests revealed serum glucose levels of $1,257 \mathrm{mg} / \mathrm{dL}$, serum osmolality of 371 $\mathrm{mOsm} / \mathrm{kg} \mathrm{H}_{2} \mathrm{O}$, creatinine levels of $3.73 \mathrm{mg} / \mathrm{dL}$, and arterial blood gas at $\mathrm{pH} 7.25$ (Table). Electrocardiography showed sinus tachycardia. The patient was diagnosed with diabetes and DKA, and was admitted to the intensive care unit for treatment. However, 20 hours after admission he developed sudden acute abdominal pain, and a subsequent blood test revealed a D-dimer level of $428 \mu \mathrm{g} / \mathrm{mL}$ (normal: 0-1.0 $\mu \mathrm{g}$ / $\mathrm{mL}$ ), fibrinogen level of $369 \mathrm{mg} / \mathrm{dL}$ (normal: 170-360 mg/ $\mathrm{dL}$ ), and fibrinogen degradation products (FDP) level of $915.6 \mu \mathrm{g} / \mathrm{mL}$ (normal: 0-9.9 $\mu \mathrm{g} / \mathrm{mL}$ ). Based on these results, acute thrombosis was suspected. Contrast-enhanced computed tomography (CT) revealed multiple thromboses in the superior mesenteric artery (SMA), superior mesenteric vein (SMV), and splenic artery (SA). In addition, edema was observed in the intestinal wall within the limits of the SMA

${ }^{1}$ Department of Diabetes, Endocrinology, and Metabolism, National Center for Global Health and Medicine, Japan and ${ }^{2}$ Department of Diabetes Research, Diabetes Research Center, National Center for Global Health and Medicine, Japan

Received for publication September 10, 2014; Accepted for publication January 5, 2015

Correspondence to Dr. Mitsuhiko Noda, mnoda@ hosp.ncgm.go.jp 
Table. Laboratory Data on Admission.

\begin{tabular}{lrlr}
\hline $\mathrm{pH}$ & 7.25 & HDL cholesterol & $27 \mathrm{mg} / \mathrm{dL}$ \\
$\mathrm{pCO}_{2}$ & $34 \mathrm{mmHg}$ & Blood urea nitrogen & $85.8 \mathrm{mg} / \mathrm{dL}$ \\
Lactate & $4.6 \mathrm{mmol} / \mathrm{L}$ & Creatinine & $3.73 \mathrm{mg} / \mathrm{dL}$ \\
Anion gap & $28 \mathrm{mEq} / \mathrm{L}$ & eGFR & $15 \mathrm{~mL} / \mathrm{min} / 1.73 \mathrm{~m}{ }^{2}$ \\
$\mathrm{HCO}_{3}^{-}$ & $14.9 \mathrm{mmol} / \mathrm{L}$ & Uric acid & $21.8 \mathrm{mg} / \mathrm{dL}$ \\
White blood cell & $10,770 / \mu \mathrm{L}$ & Sodium & $144 \mathrm{mEq} / \mathrm{L}$ \\
Red blood cell & $4,720,000 / \mu \mathrm{L}$ & Kalium & $2.6 \mathrm{mEq} / \mathrm{L}$ \\
Hemoglobin & $14.4 \mathrm{~g} / \mathrm{dL}$ & C-reactive protein & $1.33 \mathrm{mg} / \mathrm{dL}$ \\
Hematocrit & $44.4 \%$ & Plasma osmolality & $371 \mathrm{mOsm} / \mathrm{kg} \mathrm{H} \mathrm{H}_{2} \mathrm{O}$ \\
Platelet & $203,000 / \mu \mathrm{L}$ & Blood glucose & $1,257 \mathrm{mg} / \mathrm{dL}$ \\
Total protein & $6.5 \mathrm{~g} / \mathrm{dL}$ & Hemoglobin Alc $(\mathrm{NGSP})$ & $13.4 \%$ \\
AST & $14 \mathrm{U} / \mathrm{L}$ & C-peptide & $1.2 \mathrm{ng} / \mathrm{mL}$ \\
ALT & $21 \mathrm{U} / \mathrm{L}$ & Anti-GAD antibody & $<1.3 \mathrm{U} / \mathrm{mL}$ \\
$\gamma$-GTP & $126 \mathrm{U} / \mathrm{L}$ & Prothrombin time & $11.6 \mathrm{sec}$ \\
Creatine kinase & $401 \mathrm{U} / \mathrm{L}$ & PT-INR & 1.02 \\
Creatine kinase MB & $9 \mathrm{U} / \mathrm{L}$ & APTT & $20.4 \mathrm{sec}$ \\
Amylase & $578 \mathrm{U} / \mathrm{L}$ & Fibrinogen & $260.4 \mathrm{mg} / \mathrm{dL}$ \\
Triglyceride & $1,046 \mathrm{mg} / \mathrm{dL}$ & Urine ketone body & $1+$ \\
Total cholesterol & $341 \mathrm{mg} / \mathrm{dL}$ & Urine osmolality & $588 \mathrm{mOsm} / \mathrm{kg} \mathrm{H} \mathrm{H}_{2} \mathrm{O}$ \\
\hline
\end{tabular}

$\mathrm{HCO}_{3}{ }^{-}$: hydrogen carbonate ion

AST: aspartate transaminase

ALT: alanine transaminase

$\gamma$-GTP: gamma- glutamyl transpeptidase

HDL cholesterol: high-density lipoprotein cholesterol

eGFR: estimated glomerular filtration rate

Anti-GAD antibody: anti-glutamic acid decarboxylase antibody

PT-INR: prothrombin time international normalized ratio

APTT: activated partial thromboplastin time
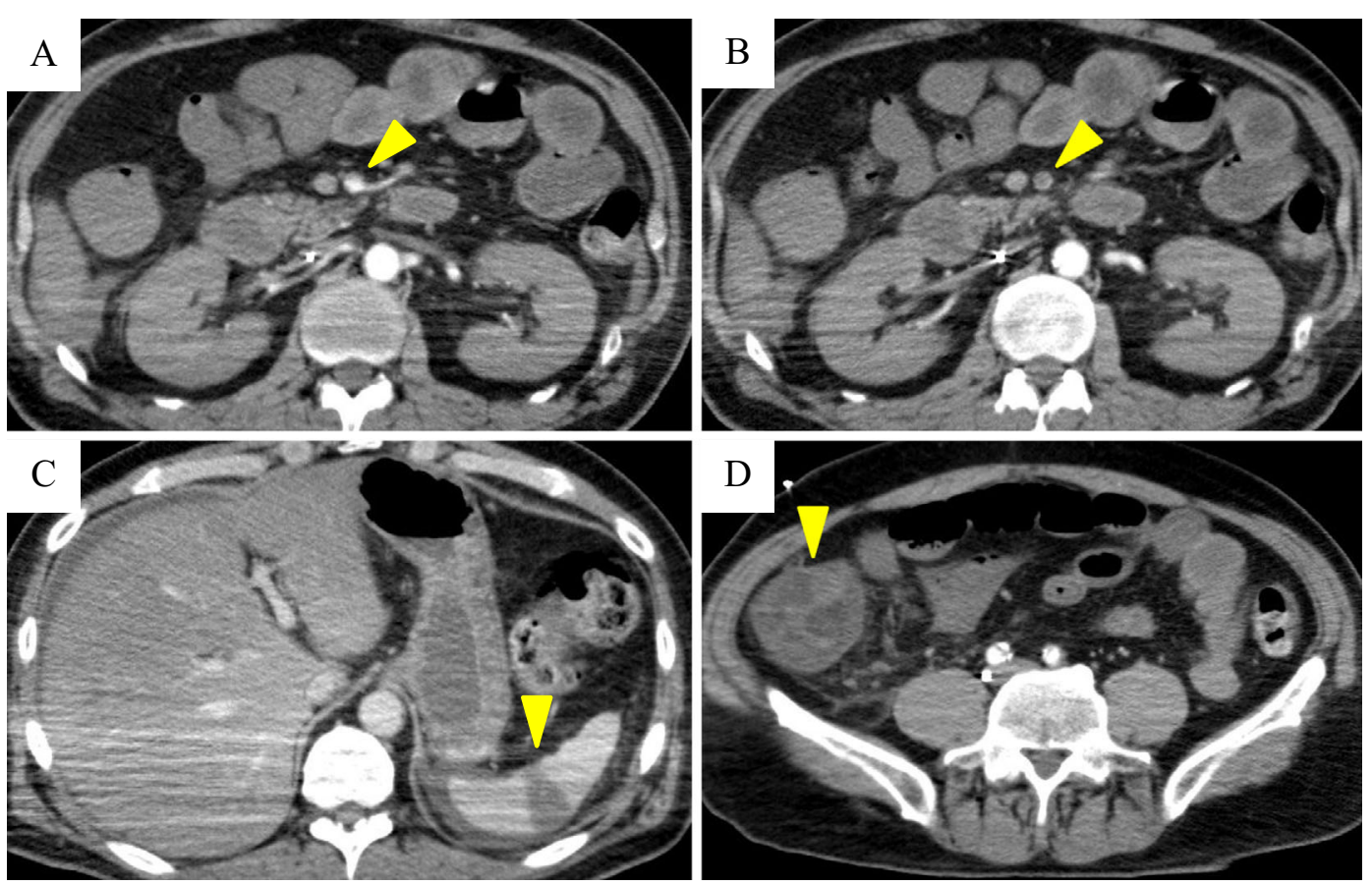

Figure 1. Contrast-enhanced abdominal computed tomography at $24 \mathrm{~h}$ after admission. A: Below $2-3 \mathrm{~cm}$ origin of the superior mesenteric artery (SMA) (arrowhead). B: Complete occlusion of the distal SMA (arrowhead). C: Splenic infarction (arrowhead). D: Edema and poor blush of the intestinal wall within the limits of the SMA (arrowhead).

(Fig. 1). Intravenous heparin was therefore initiated at $20,000 \mathrm{U} / \mathrm{day}$, and the necrotic intestines were promptly resected. During surgery, ultrasonography revealed an absence of blood flow to the lower right foot, and a thrombectomy of the right femoral artery was performed on the same day. Pathological examination revealed thickened intima of atherosclerotic arteries; however, the causal thrombus could not be sufficiently evaluated. Although arterial blood flow to the 


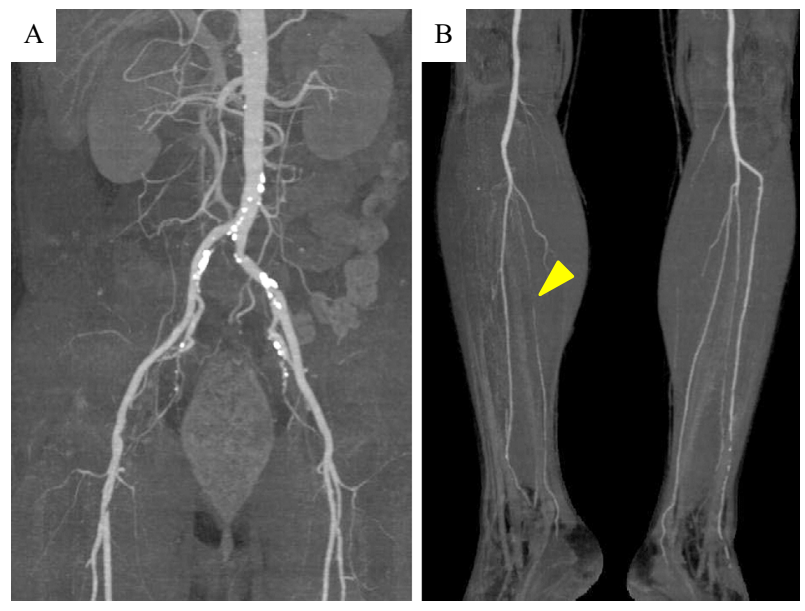

Figure 2. Contrast-enhanced lower extremity vascular computed tomography at 9 days after admission. A: Arterial calcification and narrowing of the superficial right femoral artery. B: Stenosis of the right anterior and right posterior tibial arteries (arrowhead).

right leg improved thereafter, the foot became discolored over time and gangrene developed, necessitating amputation of the right leg below the knee. Further examination revealed normal protein $\mathrm{C}$ activity, and normal levels of alpha2-plasmin inhibitor-plasmin complex ( $\alpha 2 \mathrm{PIC})$, protein $\mathrm{S}$, anticardiolipin/anti-b2 glycoprotein I complex antibody (anti$\mathrm{CL} / \mathrm{b} 2 \mathrm{GPI} \mathrm{Ab}$ ), and lupus anticoagulant. The patient therefore showed no predisposition to a thrombotic tendency, and had no family history of thromboembolism.

During surgery, the patient underwent extensive bowel resection due to SMA occlusion, and his condition was thereafter complicated by short bowel syndrome. His blood glucose control was good, with a mixed injection of regular insulin at $48 \mathrm{U} /$ day in a high-calorie infusion. A diagnosis of type 2 diabetes mellitus was made, because he showed negative for anti-glutamic acid decarboxylase antibody and his insulin secretion capacity was maintained. After amputation, the left ankle-brachial index was 1.02 (normal: 0.91.3), although the left brachial-ankle pulse wave velocity was 1,437 (normal: $<1,400 \mathrm{~cm} / \mathrm{s}$ ). Ultrasonography then showed that the intima-media thickness of the left common carotid artery was $1.7 \mathrm{~mm}$. Debridement of the patient's right leg was performed because of a wound abscess and necrosis from bruising, and he was then transferred to another hospital for rehabilitation and prosthesis fitting. Recurrence of thrombus was not observed at a follow-up examination performed at our hospital.

\section{Discussion}

In the present article, we report a case of DKA complicated with multiple thromboses of the SMA, SMV, and SA. Several mechanisms are known to contribute to a diabetic prothrombotic state, including endothelial dysfunction, coagulative activation, and platelet hyperreactivity (3). In par- ticular, the platelets of patients with diabetes are characterized by dysregulation of several signaling pathways, leading to enhanced adhesion, activation, and aggregation (3). DKA has been found to promote a prothrombotic state and to activate the vascular endothelium. In our patient's case of DKA, two conditions could have contributed to the development of acute artery thrombosis: dehydration secondary to severe hyperglycemia, and atherogenic risk factors such as smoking and hypertension $(4,5)$.

Embolism and thrombosis are two principal causes of acute arterial occlusion, and the most common sources of arterial emboli are the heart, aorta, and large arteries (6). However, these precipitating conditions were not observed in our patient. After intestinal resection, the patient's body mass index (BMI) was $26.0 \mathrm{~kg} / \mathrm{m}^{2}$, and there was therefore a possibility that his obesity may have partially contributed to the thrombotic tendency (7).

In the patient's case, multiple thromboses were observed in the SMA, SMV, SA, and arteries of the right lower leg in the acute phase of DKA, with severe hyperglycemia. CT revealed arterial calcification and vascular histopathological findings indicated arteriosclerosis (Fig. 2), which possibly contributed to the formation of the thromboses. The patient was in sinus rhythm during the period before his diagnosis of thrombosis, making cardiac embolus an unlikely cause of this event. Furthermore, protein $\mathrm{C}$ activity, $\alpha 2 \mathrm{PIC}$, protein $\mathrm{S}$, anti-CL/b2GPI $\mathrm{Ab}$, and lupus anticoagulant levels were all normal, and there was no detectable predisposition to a thrombotic tendency. In our patient, the thrombus in the SMV, which was detected using postoperative CT, could have developed simultaneously in both the SMA and SMV. In addition, the thrombus in the SMV may have been caused by the SMA occlusion. It is known that the metabolic insult of DKA may also perturb the steady state of the vascular endothelium, thereby changing the hemostatic profile and resulting in a prothrombotic state (8). Many clinical instances of hypercoagulability and vascular thrombus formation in DKA have been reported. In a study of 610 patients with DKA or hyperosmolar coma during a 16-year period, six of 38 deaths were attributed to mesenteric or iliac artery thrombosis (9). However, although many cases of mesenteric artery thrombosis in DKA have been reported, few have been associated with DKA and arterial or venous occlusion.

In practice, DKA is associated with a thrombotic tendency; however, there are few reports on this association in literature. In addition, there are few reported cases of DKA and occlusion of the SMA. Therefore, it is important to recognize all complications of DKA, some of which may require emergency treatment. In cases of DKA with severe hyperglycemia and multiple arteriovenous thromboses, immediate surgical intervention and further treatment could be life-saving.

In conclusion, our case indicated that it is necessary to consider the risk of thrombosis during the initial DKA treatment. 
The authors state that they have no Conflict of Interest (COI).

\section{References}

1. Kitabchi AE, Umpierrez GE, Murphy MB, et al. Hyperglycemic crises in diabetes. Diabetes Care 27 (Suppl 1): S94-S102, 2004.

2. Quigley RL, Curran RD, Stagl RD, Alexander JC Jr. Management of massive pulmonary thromboembolism complicating diabetic ketoacidosis. Ann Thorac Surg 57: 1322-1324, 1994.

3. Vazzana N, Ranalli P, Cuccurullo C, Giovanni D. Diabetes mellitus and thrombosis. Thromb Res 129: 371-377, 2012.

4. Lin KD, Hsieh MC, Hsin SC, Hsaio ZY, Hung WW, Shin SJ. Acute brachial artery thrombosis: a rare complication of diabetic ketoacidosis. Kaohsiung J Med Sci 22: 44-48, 2006.
5. Zipser S, Kirsch CM, Lien C, Singh TM, Kang YS. Acute aortoiliac and femoral artery thrombosis complicating diabetic ketoacidosis. J Vasc Interv Radiol 16: 1737-1739, 2005.

6. Creager MA, Loscalzo J. Vascular diseases of the extremities. In: Harrison's Principles of Internal Medicine. 17th ed. Fauci A, Braunwald E, Kasper D, Longo D, Jameson J, Loscalzo J, Eds. McGraw-Hill, New York, 2008: 1570-1571.

7. Ageno W, Becattini C, Brighton T, Selby R, Kamphuisen PW. Cardiovascular risk factors and venous thromboembolism: a metaanalysis. Circulation 117: 93-102, 2008.

8. Carl GF, Hoffman WH, Passmore GG, et al. Diabetic ketoacidosis promotes a prothrombotic state. Endocr Res 29: 73-82, 2003.

9. Hamblin PS, Topliss DJ, Chosich N, Lording DW, Stockigt JR. Deaths associated with diabetic ketoacidosis and hyperosmolar coma. 1973-1988. Med J Aust 151: 439, 441-442, 444, 1989.

(C) 2015 The Japanese Society of Internal Medicine http://www.naika.or.jp/imonline/index.html 